\title{
DIGITAL WORKFLOW FOR THE ACQUISITION AND ELABORATION OF 3D DATA IN A MONUMENTAL COMPLEX: THE FORTRESS OF SAINT JOHN THE BAPTIST IN FLORENCE
}

\author{
G. Tucci * ,V. Bonora, A. Conti, L. Fiorini \\ Dept. of Civil and Environmental Engineering, University of Florence, GeCo Lab, via P.A. Micheli 8, Florence, Italy \\ grazia.tucci@unifi.it - valentina.bonora@archimetro.it - arch.a.conti@gmail.com - lidia.fiorini@gmail.com
}

\author{
Commission V, WG V/1
}

KEY WORDS: Workflow, Photogrammetry, Laser Scanning, Integrated Survey, Mobile Mapping, UAV

\begin{abstract}
:
In recent years, the GeCo Laboratory has undertaken numerous projects to digitalize vast and complex buildings; the specific nature of the different projects has resulted in a case-by-case approach, each time working on past experiences and updating not only the hardware and software tools but also the management and processing methods. This paper presents the workflow followed for the survey of the Fortress of Saint John the Baptist in Florence, an on-going interdisciplinary project. Presently Florence's main trade fair congress centre, at the same time it hosts various buildings that bear witness to the fortress's life-history, combining constructions from the Medici and Lorraine eras with recently built exhibition facilities. Now new research has been required due to the realization of new pavilions and the regeneration of the whole complex. This has included a critical survey, material testing, diagnostic investigations and stratigraphic analyses to define the building's state of preservation. The working group comprises specialists from different institutions, amongst which the Italian Military Geographic Institute, the University of Florence, the National Research Council Institute for the Preservation and Enhancement of the Cultural Heritage, and the Florence City Council.
\end{abstract}

\section{INTRODUCTION}

In a multidisciplinary project, numerous and heterogeneous data are collected: historical, chemical, material, petrographic, archaeological, etc.. We focus here only on spatial data acquired by geomatic techniques: topographic surveying, imagery and scan data, that have been recorded with an integrated approach (Grussenmeyer et Al. 2011, Voltolin et Al. 2007, Guarnieri et Al. 2006).

When it is required to digitize heritage, meeting at the same time requirements related to a high resolution and to a large-scale analysis, a massive quantity of spatial data is produced.

Acquiring spatial data, processing it and producing the required graphical outputs become challenging tasks when it is necessary to deal with huge amount of data. It is not strictly correct (not quite at a given time) to consider it as big data, that refers not only to data quantity but also to its variety, velocity, complexity, etc. [Baker 2016]. Moreover, the peculiarities of the cultural heritage field does not allow for the full exploitation of data mining, which have the makings of automatically extract information from a dataset. Cultural heritage documentation, conservation and enhancement require incisive and responsible decisions by well prepared professionals. Although human skills are still fundamental for data interpretation, ICT offers notable opportunities for improving and speeding up complex digitization processes. Conventional data processing techniques must be continually updated not only taking into account the newest hardware and software tools available, but also for defining, from time to time, the best workflow.

\subsection{Updated review of a digitization workflow}

A digitization project workflow is usually summarized as:
- Data capture;

- Data processing;

- Output presentation.

To ensure effective results, it is important to consider also:

- A preliminary design phase;

- Metadata production and recording;

- The management of the entire process;

- Safe and long term archiving of raw data and of all elaboration steps;

- Sharing options and policies.

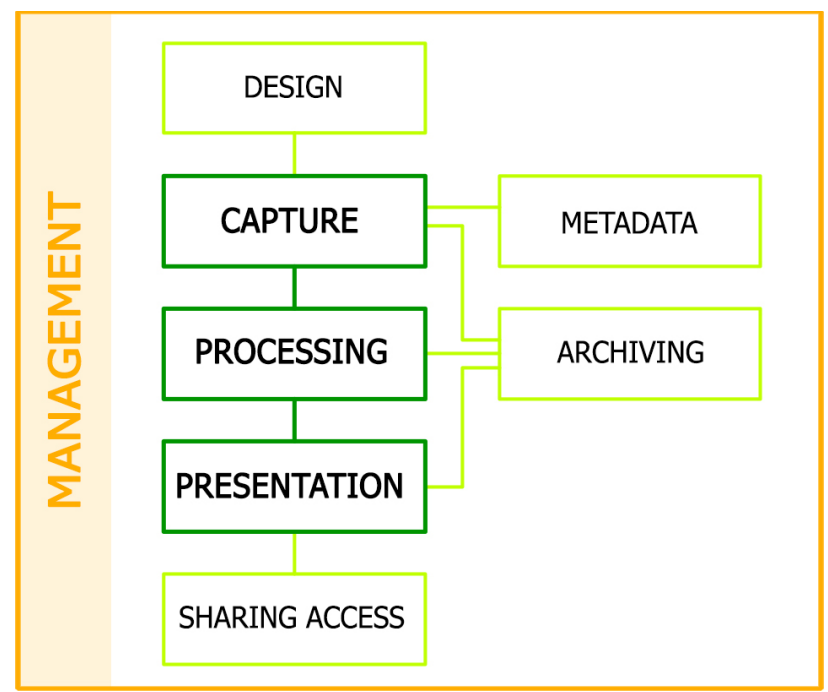

Figure 1. Outline of a digitization workflow

\footnotetext{
* Corresponding author
} 


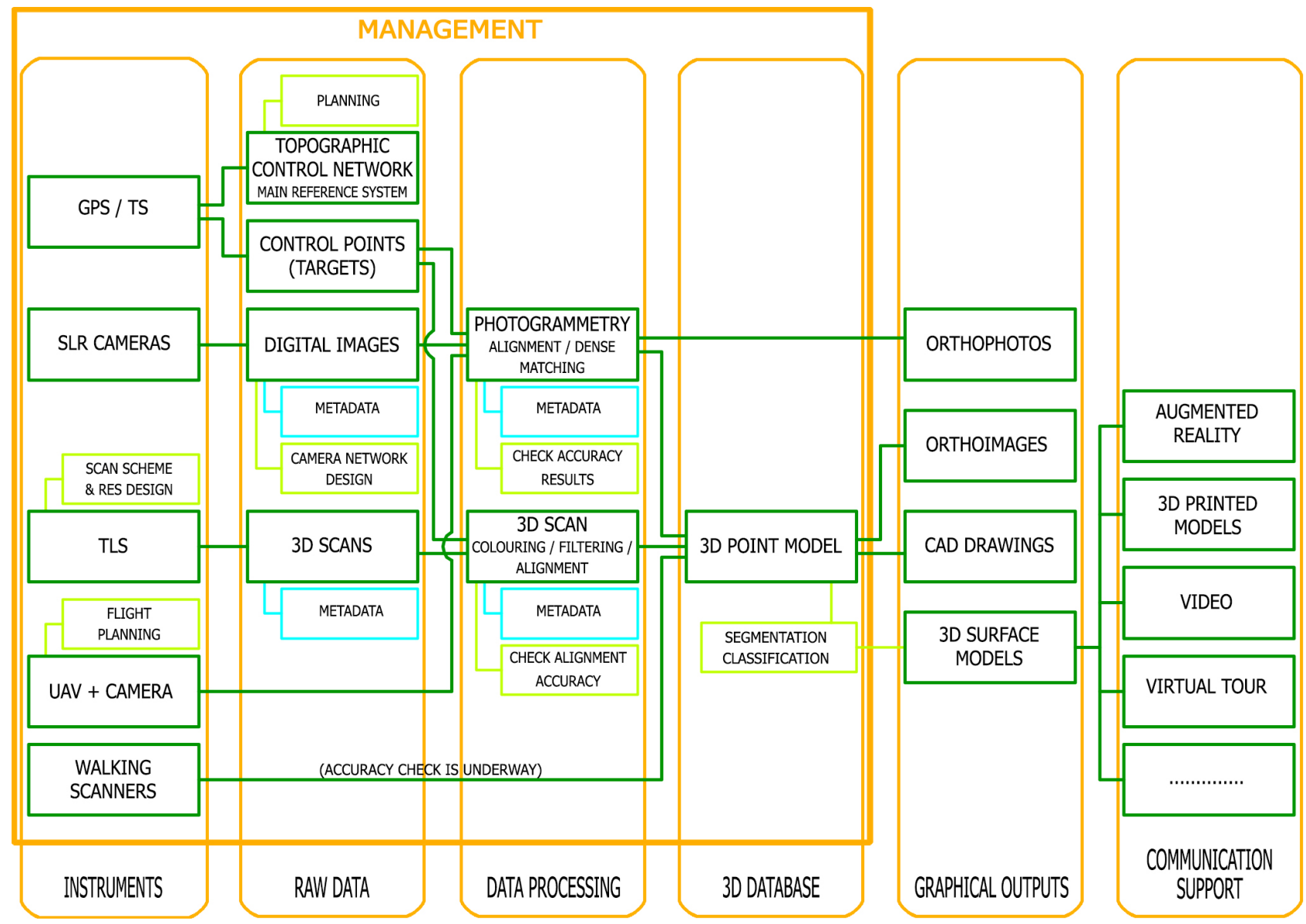

Figure 2. The digitization workflow adopted in the Fortress

\section{3D SURVEY OF A LARGE MONUMENTAL} COMPLEX

\subsection{The fortress of Saint John the Baptist (aka Fortezza da Basso) in Florence}

The complex (presently the main trade fair congress centre in Florence) hosts at the same time various buildings that bear witness to the fortress's life-history, combining constructions from the Medici and Lorraine eras with recently built exhibition facilities. The "Fortezza da Basso", built in 1534-36 along the ancient walls of Florence following the design of Antonio da Sangallo, forms an irregular pentagonal shape, with straight curtain walls and bastions at the vertices. It is composed of bricks, except for the keep, a small bastion situated facing Florence, along the longest curtain wall, which has a dog-tooth cladding made with pietra forte. The fortress covers an area of around 95,000 sq $\mathrm{m}$, the walls are 1,500 $\mathrm{m}$ long, with an average height of $10 \mathrm{~m}$, creating a total surface area of over $15,000 \mathrm{sq} \mathrm{m}$. The walls and bastions are defensive machines carefully designed following Renaissance military art. They contain firing positions, storerooms and passageways that run underground along the entire perimeter.

Originally on the outskirts of the city, the fortress is currently surrounded by several traffic lanes and in part by public gardens. (Gurrieri et Al. 1990; Guidi et Al, 1988)

\subsection{An interdisciplinary project}

This paper presents the workflow followed for the survey of the Fortress of Saint John the Baptist in Florence, an on-going interdisciplinary project. New research has been required due to the realization of new pavilions and the refurbishment of the entire fortress. This has included a critical survey, material testing, diagnostic investigations and stratigraphic analyses to define the building's state of preservation. The working group comprises specialists from different institutions, amongst which are the Italina Military Geographic Institute, the University of Florence, the National Research Council Institute for the Preservation and Enhancement of the Cultural Heritage, and the Florence City Council.

\subsection{Graphical output}

The immediate goals of the documentation project were agreed upon with the other study groups involved and can be summed up as follows:

- documentation of the external wall facings reproducible with a level of detail enabling representation at a scale of $1: 50$,

- documentation of all the internal spaces with the production of a general location plan enabling representation at a scale of $1: 100$,

- metric documentation of the underground passageways enabling restoration and visitor access,

- documentation of the ramparts and the roofs of the internal buildings.

\section{MAIN ISSUES}

The range of potentials provided by a 3D model of an architectural complex make it difficult to generalize the procedures to apply, to pinpoint the "best" tool, and to define universally useful modes of 


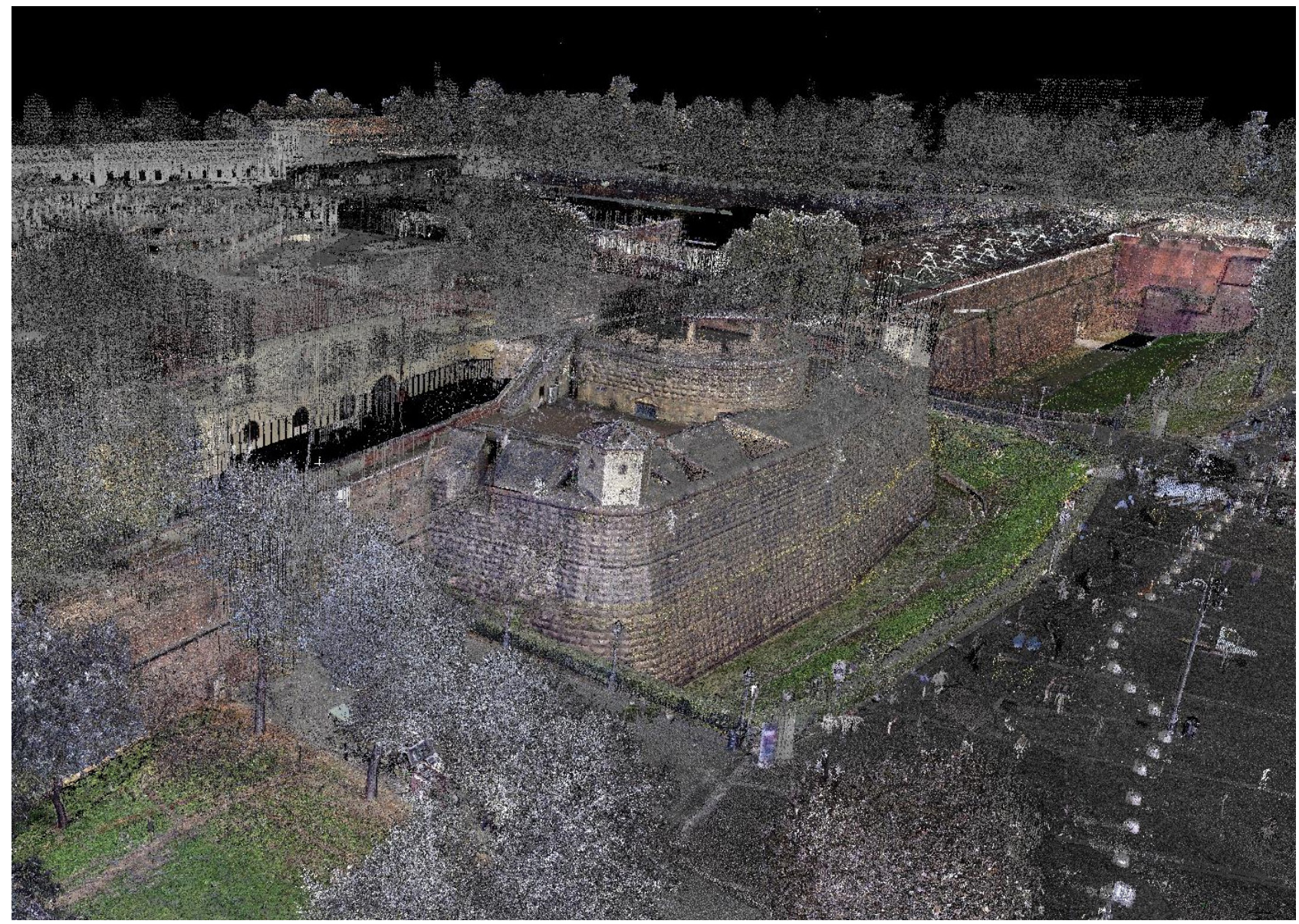

Figure 3. View of the fortress: the 3D point model comes from digital photogrammetry, TLS, mobile mapping systems

representation. For example, structural analyses require 3D models with a low level of detail, but also complete information on the structures as well as time-consuming hypotheses concerning their material composition. Surface cleaning and restoration operations require high-resolution mapping with photographic contents (orthophotos) enabling the identification and decay of materials, and the planning and documentation of restoration work. Reuse and development projects require traditional graphical output, as plans and sections. Lastly, non-specialist audiences can be informed of both the current state of preservation and any planned interventions through rendered 3D models or interactive visualization systems. For the reasons just given, broad guidelines are lacking in the cultural heritage field. For the production of maps, on the other hand, there are generally specifications outlining the surveyor's tasks beforehand, in view of the client's needs. Standards concerning representation are also more common.

In order to undertake such a wide and complex task as the digitalization of the fortress, several issues have to be considered. In the following, the solutions adopted are described.

\subsection{Alternative or integrated application of photogrammetry and 3D scanning systems}

High resolution orthoimages were required to document different wall textures and materials. The other specialists participating in the project also used them as a sketch to record in the field their annotations. Despite some interesting attempts for automatic recognition of materials, decay, cracks patterns (Sidiropoulos et Al. 2017), it is actually a task that requires very specialized skills. Where possible, photogrammetry has been used, as the high- resolution orthophotos allow all the other specialists to immediately acquire the details necessary. On the other hand, a photogrammetric project requires pictures taken from a long distance without any visual obstacle, which is impossible where there are roads with heavy traffic or in the presence of vegetation next to the walls. In these cases, it was therefore preferred to perform surveys with laser scanners, which enabled the production of orthoimages from the point cloud instead. A comparison between photogrammetric orthophotos and orthoimages based on TLS data is presented in (Tucci et Al. 2016).

A laser scanner Z+F 5010c has been used and thanks to its integrated camera and to HDRI technique, the rendered quality of orthogonal views of the point model is comparable to that provided by photogrammetric orthophotos.

Some pros and cons of both techniques, cencerning this project, are:

- Photogrammetry requires more targets to be positioned over all the walls with an expensive aerial work platform; on the other hand, laser scanner targets are larger and more invasive.

- Resolution: elaborating scan data, the requested resolution is barely reached;

- Pre-elaboration steps: photos require some image enhancement that can be applied as a batch process, scans cleaning of undesired data must be manually performed.

\subsection{Potentials and limits assessment of mobile systems transported on vehicles or trolleys}

Conceptual design and prototyping of mobile mapping systems date back to the 1990's (Novak 1992); their development is still 


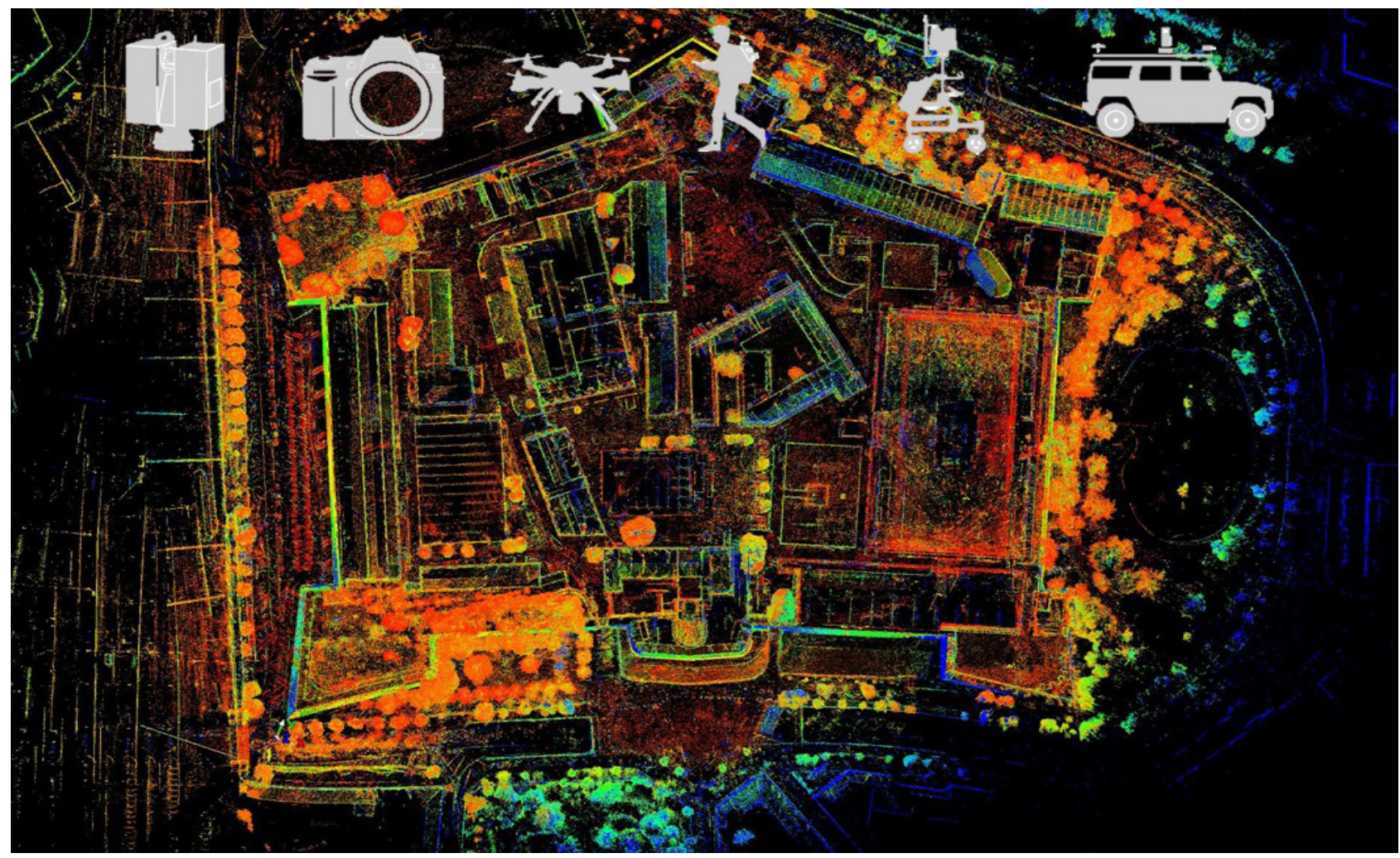

Figure 4. View of the complete point model, acquired by different techniqies and instruments

in progress: increasing the speed of the vehicles, the accuracy and the resolution of data, the user-friendliness of the management interface.

A first test was performed inside the fortress, covering almost all the inner paths and buildings by a MMS composed of a car equipped with a Riegl VMZ system, a SLR camera, IMU/GNSS, and a control unit. The scanner operates as profilometer but, at the same time, it rotating around its main axis. This setting allows the acquisition of more complete data even with just one scanner. Pros: very quick acquisition of all areas accessible by the car. Cons: some issues in time synchronization between camera and scanner did not permit the application of RGB values to the scans.
A second test on the external walls was made using a $\mathrm{Z}+\mathrm{F}$ 5010 scanner mounted on a special trolley (ProScan, by Leica Geosystems) provided by a IMU, GNSS antenna and receiver, and a $360^{\circ}$ reflector prism for tracking the system by a robotic total station.

Pros: Expeditious acquisition in the field; no alignment phase needed.

Cons: the laser scanner works as a profilometer, acquiring only geometry and intensity data; the trolley must be pushed around on a quite level surface: a pavement is ok but a lawn is not; a topographic support is required for places without GNSS support (inner spaces and some narrow passages); vertical resolution can

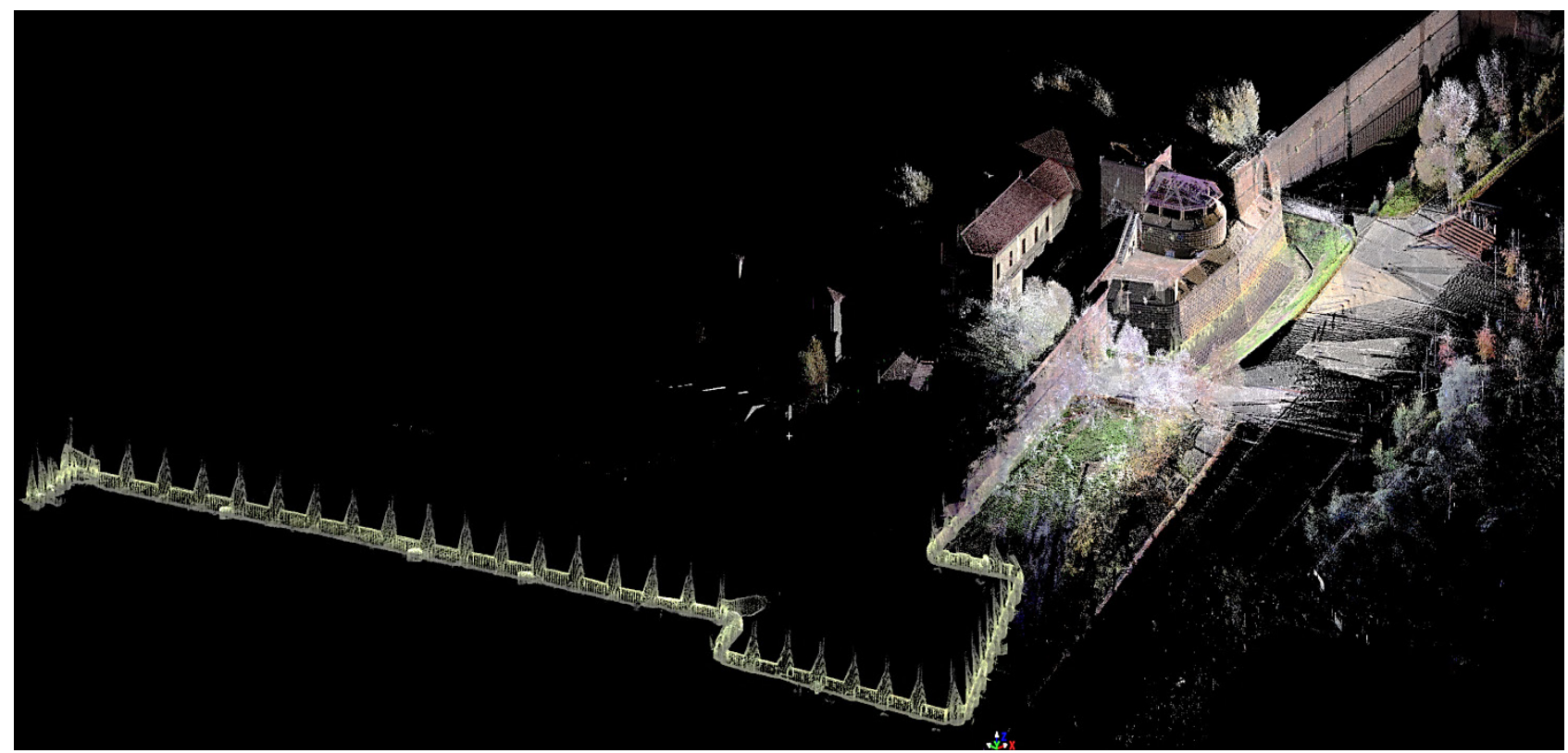

Figure 5. The entrance of the fortress and the underground passageways acquired by "walking scanners" 

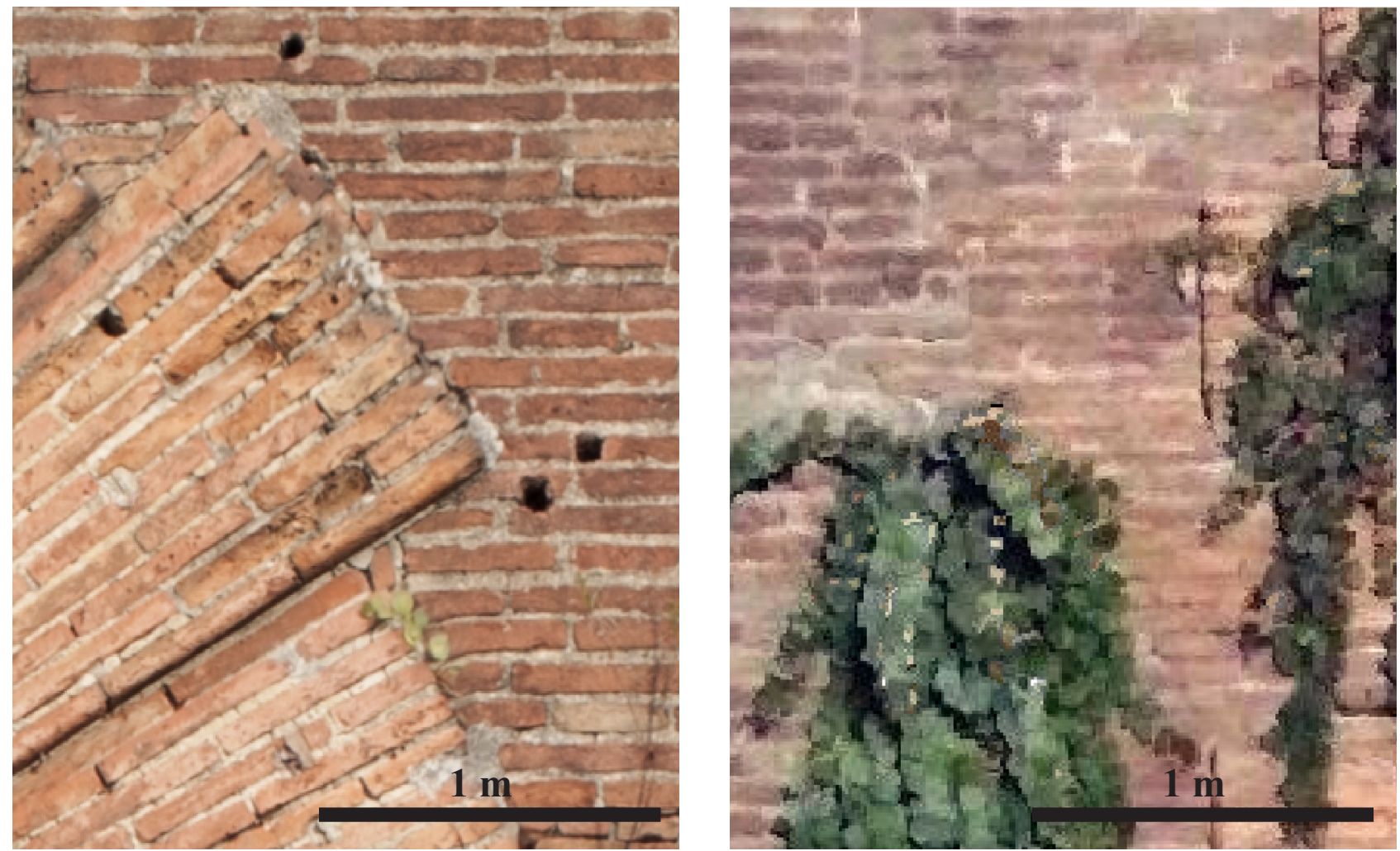

Figure 6. A sample of ortophoto (left, by a photogrammetric processing) and of ortoimage (right, by laser scanning processing) - the sampling are enlarged to make evident the difference between orthophoto and orthoimage; at the original print scale (1:100) the images quality is almost equivalent.

be set up, while the horizontal resolution depends on the motion speed.

General remarks concerning mobile mapping systems for this documentation project are:

- both systems that have been tested could provide useful data for a preliminary survey only, that must be more detailed later with different instruments;

- the data obtained proved to be useful to place the complex within the urban context; nevertheless, the accuracy and above all the resolution obtained resulted insufficient for the aims set.

- as with all mobile systems, they provide data without normals, that are indispensables for rendering data with shading algorithms and for optimizing the alignment of datasets with ICP.

\subsection{Underground passageways survey with "walking scanners"}

Different solutions for man-portable mapping systems have recently appeared on the market (Akhka personal laser scanner, Trekker by Google, Zebedee system, Leica Backpack) (Kukko et Al. 2016, Lin 2014, Bosse et Al. 2012, Cantoro et Al. 2015, Nuekter et Al. 2015). They look very promising for acquiring fast and cost-effective indoor and outdoor digitization. A different solution for documenting complex underground structures is proposed in (Troisi et Al. 2017).

Under the fortress walls there is a passageway, currently interrupted in some areas; it presents some irregularity on the ground and some small rooms and its path turns under the bastions. The stretch chosen for testing the Leica Pegasus Backpack and GeoSLAM Zeb-Revo systems is about $500 \mathrm{~m}$ long, with alternating straight paths and bends. With both instruments, the lack of a GPS signal due to the indoor operations is solved by using SLAM techniques. Comparison and assessment of the acquired data are underway.

\subsection{Documentation of areas inaccessible to ground surveys with UAV}

For integrating the digital model acquired from the ground a low height photogrammetric fly has been planned. UAV are ever more frequently used for similar mapping projects (Cardenal et Al. 2016 , Kersten et Al. 2015, Fallavolita et Al. 2017). For flying over the Fortress of Saint John, a special permission had to be acquired, following Italian regulations, both because the fortress is in the city centre and not far from the Florence's airport. In these situations, it is important to consider the waiting period for authorization. A wide pruning of the vegetation over growing the bastions has been indispensable for effectively documenting these structures.

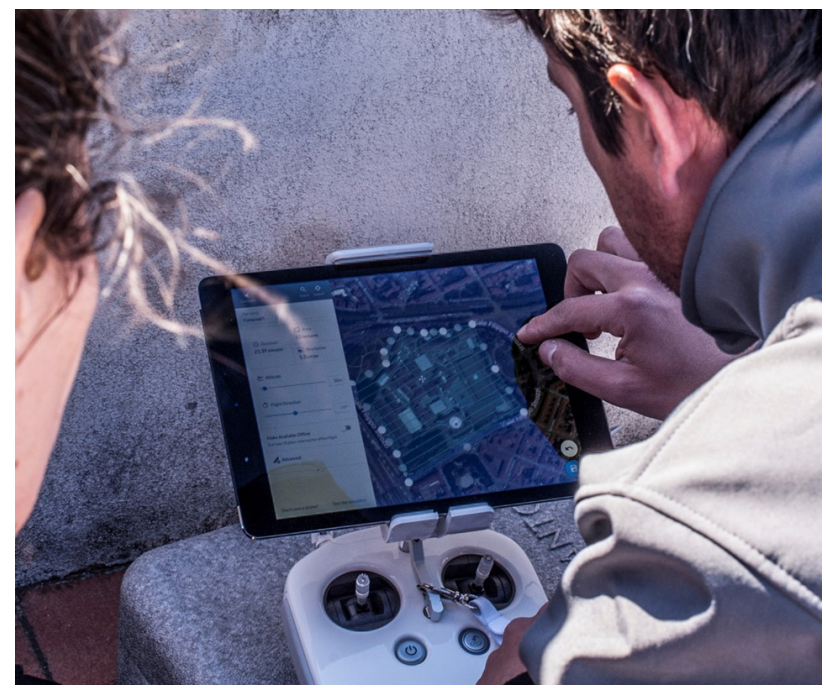

Figure 7. Set up of the UAV fly controller according to the planned parameters 


\subsection{Different reference systems management}

The laser scans are aligned in the topographic system; from this, suitable local reference systems need to be defined in order to make the orthoimages. Conversely, the coordinates of the photogrammetric projects are initially expressed in local reference systems, and then need to be transformed so that all the data can be combined in the general reference system.

\begin{tabular}{|c|c|}
\hline \multicolumn{2}{|c|}{ SUMMARY TABLE } \\
\hline Acquisition campaigns & $\begin{array}{l}\text { September-December } 2015 \\
\text { January-February } 2016 \\
\text { September-December } 2016 \\
\text { January-March } 2017\end{array}$ \\
\hline Field personnel & 2-3 (scanning - photogrammetry) \\
\hline $\begin{array}{l}\text { Terrestrial Photogrammetric } \\
\text { Imagery - wall facings }\end{array}$ & 3.089 \\
\hline Ground Control Points & 127 \\
\hline Check Points & 68 \\
\hline Ground Sample Distance & $<5 \mathrm{~mm}$ \\
\hline $\begin{array}{l}\text { UAV Photogrammetric Imagery } \\
\text { - roofs }\end{array}$ & 952 \\
\hline $\begin{array}{l}\text { UAV Photogrammetric Imagery } \\
\text { - wall walks }\end{array}$ & 1.543 \\
\hline Ground Control Points & 69 \\
\hline Ground Sample Distance & $<11 \mathrm{~mm}$ \\
\hline 3D scans & 725 \\
\hline Targets & 155 \\
\hline TLS Measured points & 19.663.397.347 pts \\
\hline Mobile mapping & $215.754 .063 \mathrm{pts}$ \\
\hline Walking scanner - Zeb REVO & $59.022 .898 \mathrm{pts}$ \\
\hline $\begin{array}{l}\text { Walking scanner - Leica- } \\
\text { Backpack }\end{array}$ & $270.874 .692 \mathrm{pts}$ \\
\hline Database 3D point model (.IMP) & $388 \mathrm{MB}$ \\
\hline Hardware & $\begin{array}{l}\text { Z+F 5010C Laser scanner } \\
2 \text { Nikon D } 700 \text { full frame cameras } \\
20 \mathrm{~mm}, 24 \mathrm{~mm}, 35 \mathrm{~mm}, 50 \mathrm{~mm} \text {, } \\
200 \mathrm{~mm} \text { lenses } \\
\text { ProScan (Leica Geosystems) } \\
\text { Laser scanner Riegl VMZ } \\
\text { Pegasus Backpack (Leica Ge- } \\
\text { osystems) } \\
\text { Zeb-Revo (GeoSLAM) }\end{array}$ \\
\hline Software & $\begin{array}{l}\text { Z+F Laser Control (range maps } \\
\text { RGB processing) } \\
\text { Leica Cyclone (range maps } \\
\text { processing), } \\
\text { Microstation (CAD) } \\
\text { AutoCAD (CAD) } \\
\text { JRC Reconstructor e JRC R3 } \\
\text { (orthoimages) } \\
\text { MeshLab (mesh modelling) } \\
\text { Adobe Photoshop (editing) }\end{array}$ \\
\hline
\end{tabular}

Table 1. Summary of the most relevant data of the project

\section{PERSPECTIVE AND FUTURE WORK}

\subsection{Automatic modelling procedures}

Point cloud segmentation can be exploited for introducing a certain level of organization to the data thus allowing the extraction of useful information (Filin and Pfeifer 2006), or as a precursor to

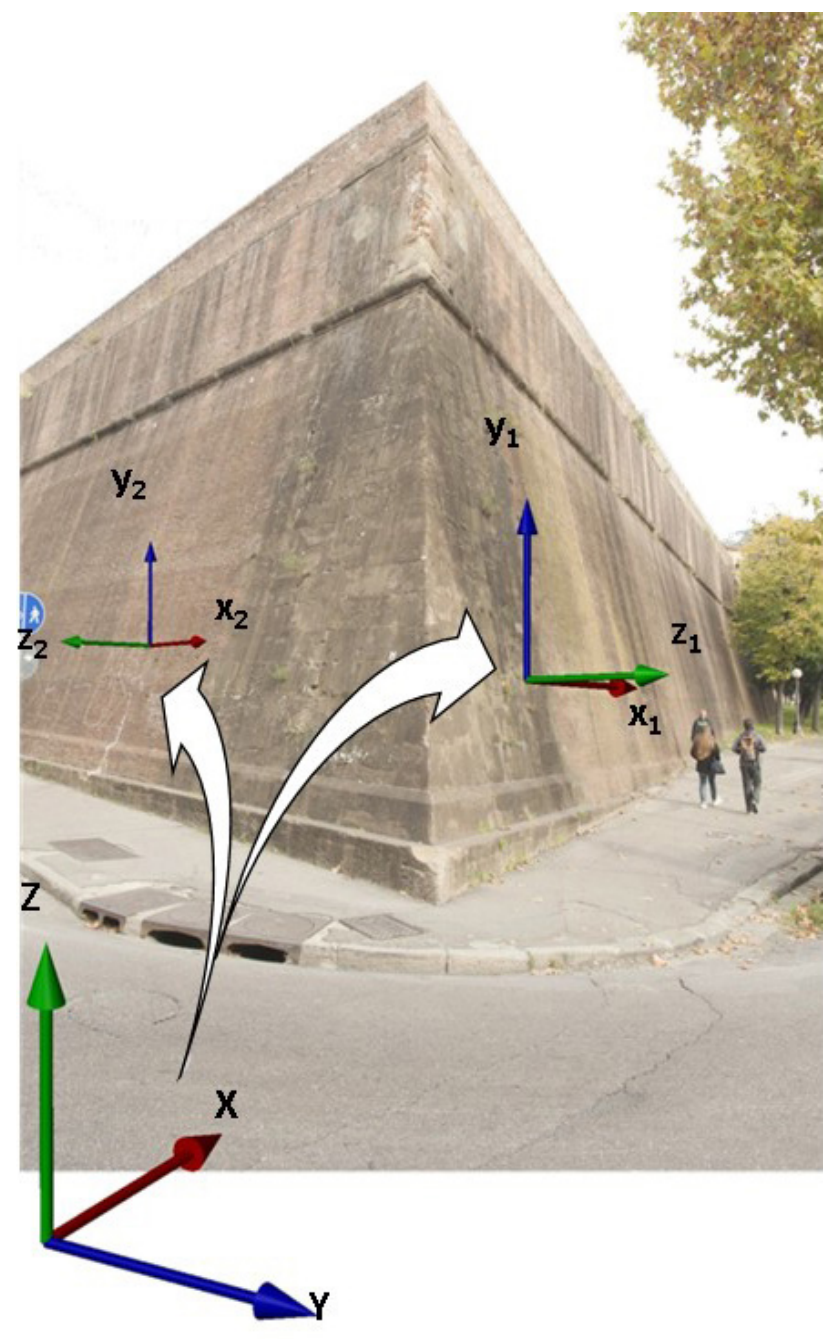

Figure 8. Different reference systems managed in the project: scan data are directly refered to the main r.s. (topographically defined by the control network) while photogrammetric GCP and $\mathrm{CP}$ need to be roto-tranlasated in local r.s.; the photogrammetric point model are then roto-tranlated back to merge all the data in the final 3D dababase

object recognition and model fitting (Crosilla et Al. 2009). It can be also employed as a preprocessing step before the application of filtering algorithms (Tovari and Pfeifer 2005).

Once a point cloud has been segmented, each segment (group) of points can be labelled with a class, thus giving some semantic definition to each segment (point cloud classification is often called semantic segmentation or point labelling).

\section{CONCLUSIONS}

This paper aims to present the general workflow that has been adopted for the data acquisition and management in the wide ranging digitization project concerning the Fortress of Saint John the Baptist in Florence. The studies, involving a multidisciplinary team, are still underway and further results, and detailed analysis of all the steps here summarized will be soon published.

\section{ACKNOWLEDGMENTS}

The presented project has been developed in the framework of the agreement between the University of Florence-DICEA Dept. and the Municipality of Florence "New studies, survey and analysis 


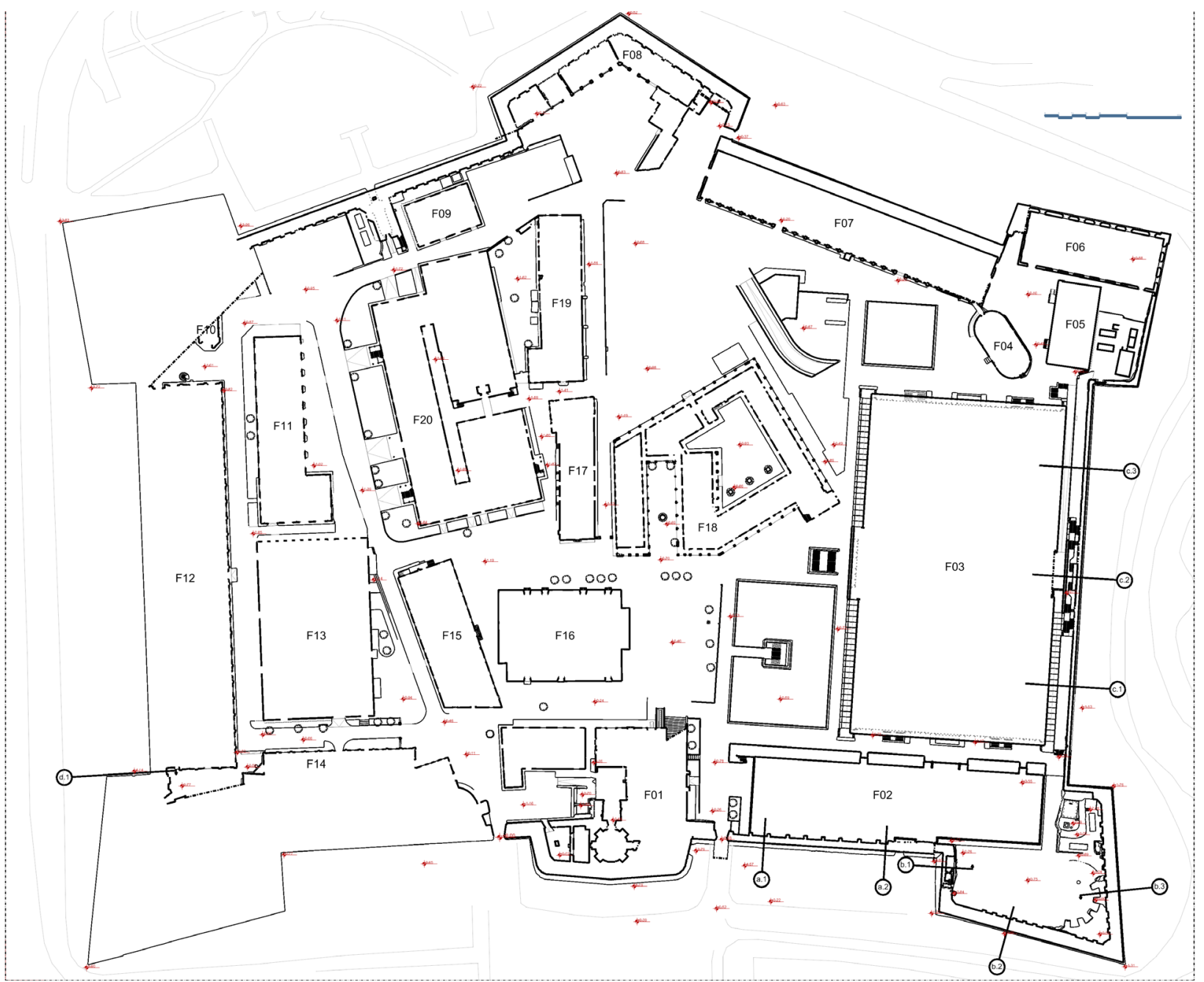

Figure 9. Plan of the fortress - orignal drawings in scale 1:500 - 1: 200

aimed to verify the conservation status of the Fortezza da Basso in Florence".

This project has been partially supported by PRIN2015 - GAMHer

- Geomatics data acquisition and Management for landscape and built Heritage in a European perspective (founded by Italian Ministry of education, university, and research).

Leica Geosystems, Me.s.a. s.r.l., and Microgeo s.r.l. kindly offered their support for testing mobile mapping systems and walking scanners.

Drone Arezzo s.r.l. performed the UAV flight.

Francesca Panighini collaborated to the project, being in charge of the plan drawing.

Niccolò de Ruvo is preparing his degree thesis about data segmentation and classification working on the fortress dataset.

\section{REFERENCES}

Baker, R., 2016. Big Data: A Survey Research Perspective. In: Proceedings of Statistics Canada Symposium 2016 Growth in Statistical Information: Challenges and Benefits, Québec, Canada.

Beraldin, J. A., Remondino, F., Shortis, M. R., (editors), San Jose, CA, United States, Vol. 6491

Bosse, M., Zlot, R., Flick, P., 2012. Zebedee: Design of a springmounted $3 \mathrm{D}$ range sensor with application to mobile mapping. IEEE Transactions on Robotics, 28(5), pp. 1104-1119.
Cantoro, G., Sythiakakis, V., Manolioudis, S., 2015. Visualizing Structural Issues Through Photogrammetric 3D Documentation of Cultural Heritage: the Venetian Sea-Fortress at Herakleion, Crete, Greece. In: THE FUTURE OF THE PAST: From Amphipolis to Mosul, New Approaches to Cultural Heritage Preservation in the Eastern Mediterranean, Chalikias, K., Beeler, M., Pearce, A., Renette, S., (Editors), Heritage, conservation \& archaeology Archaeological Institute of America, pp.80-86.

Cardenal, J., Pérez, J. L., Mata, E., Delgado, J., Gómez-López, J. M., Colomo, C., and Mozas, A., 2016. Recording and modeling of fortresses and castles with UAS. Some study cases in jaen (Southern Spain). In: The International Archives of the Photogrammetry, Remote Sensing and Spatial Information Sciences, Prague, Czech Republic, Vol. XLI-B5, pp. 207-214.

Crosilla, F., Visintini, D., Sepic, F., 2009. Reliable automatic classification and segmentation of laser point clouds by statistical analysis of surface curvature values (2009). In: Applied Geomatics, 1 (1-2), pp. 17-30. DOI: 10.1007/s12518-009-0002-4

Fallavollita, F., Ugolini, A., 2017. New methodologies for the documentation of fortified architecture in the state of ruins. In: The International Archives of the Photogrammetry, Remote Sensing and Spatial Information Sciences, Folorence, Italy, Vol. XLII-5/ W1, pp. 411-418. 
Grussenmeyer, P., Alby, E., Assali, P., Poitevin, V., Hullo, J. F., Smigiel, E., 2011. Accurate Documentation in Cultural Heritage by merging TLS and high resolution photogrammetric data In: Proceedings of SPIE, Videometrics, Range Imaging, and Applications XI, Remondino, F., Shortis, M. R., (editors), Munich, Germany, Vol. 8085

Guarnieri, A., Remondino, F., Vettore, A., 2006. Proceedings of ISPRS Commission V Symposium, Image Engineering and Vision Metrology, "Digital photogrammetry and TLS data fusion applied to Cultural Heritage 3D modelling", Dresden, Germany, http:// www.isprs.org/proceedings/XXXVI/part5/paper/1216_Dresden06. pdf

Guidoni Guidi, G., 1988. Notizie preliminari su alcuni ritrovamenti effettuati a Firenze: Piazza della Libertà - Viale S. Lavagnini; la Fortezza da Basso. In: Archeologia Medievale, Numero 15, pp. $407-416$

Gurrieri, F., Mazzoni, P., 1990. La Fortezza da Basso. Un monumento per la città, ed. Ponte alle Grazie, Firenze.

Kersten,T., Mechelke, K., Maziull, L., 2015. 3D model of al zubarah fortress in qatar - Terrestrial laser scanning vs. Dense image matching. In: The International Archives of the Photogrammetry, Remote Sensing and Spatial Information Sciences, Avila, Spain, Vol. XL-5/W4, pp.1-8.

Kukko, A., Kaartinen, H., Virtanen, J.-P., 2016. Laser Scanner in a Backpack. In: GIM International. https://www.gim-international. com/content/article/laser-scanner-in-a-backpack

Lin, S., 2014. Making of Maps: The cornerstones. https://maps. googleblog.com/2014/09/making-of-maps-cornerstones.html
Novak, K., 1992. Real-Time Mapping Technology, In: The International Archives of the Photogrammetry, Remote Sensing and Spatial Information Sciences, Washington, D.C., USA, Vol. XXIX-B2, pp.569-575.

Nuechter, A., Borrmann, D., Koch, P., Kuehn, N., May, S., 2015. A man-portable, imu-free mobile mapping system. In: ISPRS Annals of the Photogrammetry, Remote Sensing and Spatial Information Sciences, La Grande Motte, France, Vol. II-3/W5, pp. 17-23.

Sidiropoulos, A. A., Lakakis, K. N., Mouza, V.K., 2017. Localization of pathology on complex architecture building surfaces. In: The International Archives of the Photogrammetry, Remote Sensing and Spatial Information Sciences, Nafplio, Greece, Vol. XLII-2/W3, pp. 617-621.

Troisi, S., Baiocchi, V., Del Pizzo, S., Giannone, F., 2017. A prompt methodology to georeference complex hypogea environments. In: The International Archives of the Photogrammetry, Remote Sensing and Spatial Information Sciences, Nafplio, Greece, Vol. XLII-2/W3, pp. 639-644.

Tucci, G., Bonora, V., Fiorini, L., Conti, A., 2016. The Florence Baptistery: 3-D survey as a knowledge tool for historical and structural investigations, In: The International Archives of the Photogrammetry, Remote Sensing and Spatial Information Sciences, Prague, Czech Republic, Vol. XLI-B5, pp. 977-984.

Voltolini, F., El-Hakim, S., Remondino, F., Pontin, M., Girardi, S., Rizzi, A., Gonzo, L., 2007. Digital documentation of complex architectures by integration of multiple techniques - The case study of Valer Castle, In: Proceedings of SPIE, Videometrics IX,

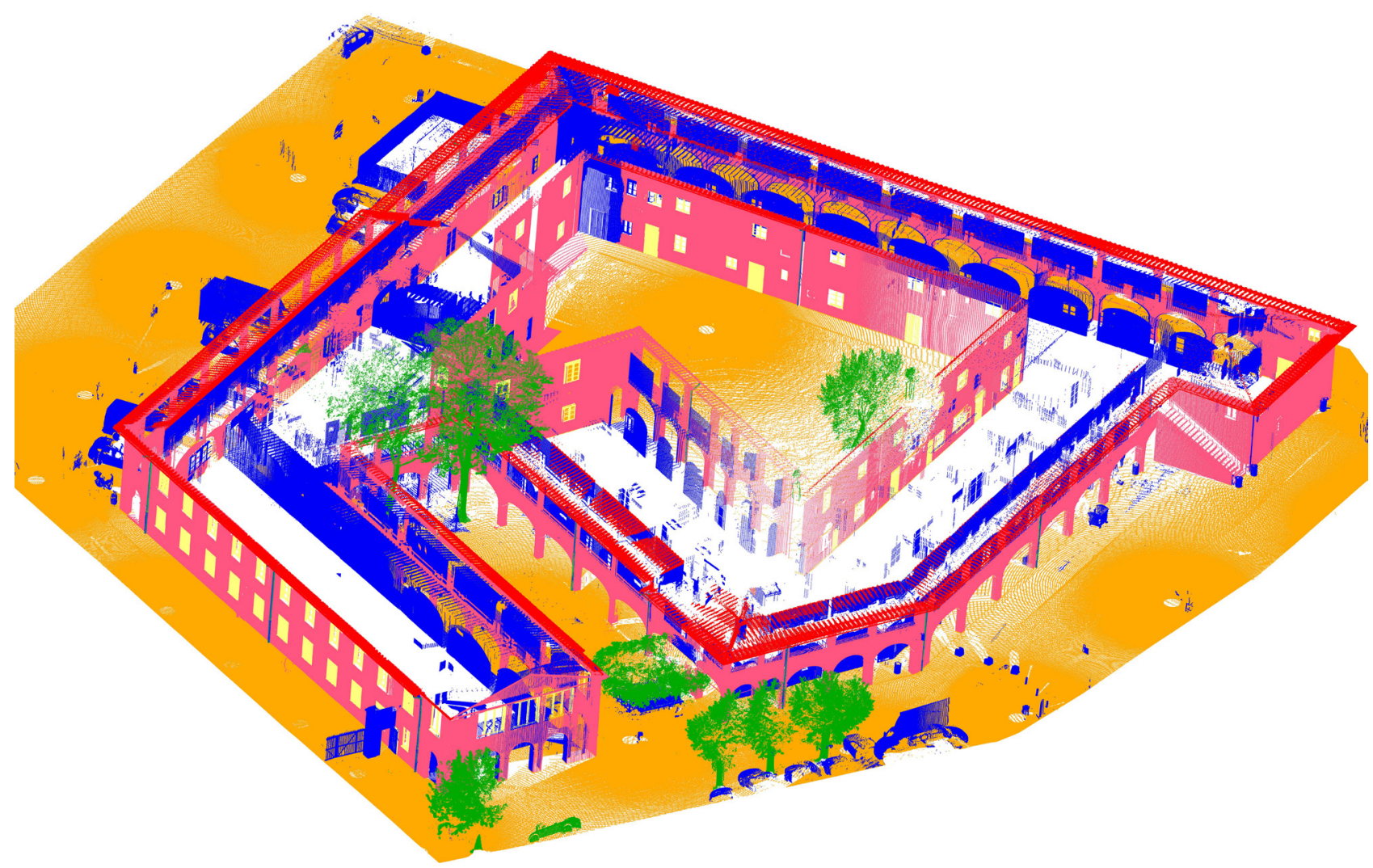

Figure 10. Test about data segmentation on a building inside the fortress 